Original Article

\title{
Role of Social Networks in Raising the Level of Self-Care of Pregnant Women
}

\author{
Ghasem Deimazar, Mehdi Kahouei, Mozhgan Rahmanian, Neda Motamednejad,
} Parnian Mehrabi

\section{ABSTRACT}

OBJECTIVES: To introduce the role of online social networks in raising the level of self-care of pregnant women.

METHODOLOGY: This was a observational cross-sectional study. Four hundred and four pregnant women were estimated as sample using the sample size estimation of Cochran (confidence level of 95\%), among the ones who referred to outpatient clinic and inpatients of Amir Almomenin hospital of Semnan, Iran. The questionnaire used in this study included three sections and the authors developed it after reviewing the related literatures. The questionnaire was tested as pilot on 28 pregnant women which were randomly chosen from Amir Almomenin hospital.

RESULTS: Our Study showed that the highest average score of using the pregnant women from social networks was to use the experience of pregnant women who had a child aged $3.46 \pm 1.33$ and also related to the concerns of the pregnant women due to differences in the information of physicians and social network users $2.67 \pm 1.34$. The findings showed that there were significant relationships between some of the individual characteristics of pregnant women and their use of social networks $(P<0.01)$.

CONCLUSION: According to the findings of this research, electronic communication between pregnant women and the clinical staff (midwives and physicians) through social media requires the promotion of social network use by this group. It thus seems necessary to encourage physicians to use social media to properly monitor their patients' maternal and fetal health.

KEYWORDS: Social network, Self-care, Pregnant women

This article may be cited as: Deimazar G, Kahouei M, Rahmanian M, Motamednejad N, Mehrabi P. Role of Social Networks in Raising the Level of Self-Care of Pregnant Women. J Liaquat Uni Med Health Sci. 2018;17(03):135-40. doi: 10.22442/jlumhs.181730565

\section{INTRODUCTION}

Social media represent a group of internet-based software that have been made based on the ideology and technology known as web 2.0. Social media allow the creation and exchange of content made by the users ${ }^{1}$. Social media allow individuals to participate in online social networks and communicate with each other in an interactive dialogue ${ }^{2}$.

One of the factors involved in the success of social media is that many of them are free of charge ${ }^{1}$. Social media play an important role in the contemporary society and are used for various purposes, such as finding a job, finding friends, gaining information and sharing everyday life experiences. Moreover, a large number of people in the community use mobile devices such as smartphones and tablets that allow them to use social media at any time and in any place ${ }^{1}$. Social media allow users to communicate effectively and have access to a variety of information $^{1,3}$. Pregnant women comprise one of the groups that can use social media to upgrade their knowledge base and increase their health literacy and self-care during pregnancy. Self-care is recognized as a health-promoting behavior that constitutes a valuable step toward raising awareness and helping patients gain personal autonomy and facilitating their adaptation to their illness and consequently improving their quality of life ${ }^{4}$. Communities of pregnant women are one of the groups that can perform self-care through online social networks and thus guarantee their own and their children's health using self-care at home. Self-care during pregnancy consists of a set of care principles and plans that can lead to desired pregnancy outcomes ${ }^{5,6}$. Pregnancy care can reduce the risk of maternal mortality and pregnancy or 
childbirth problems by identifying and reducing the potential risks of pregnancy and helping women correct behavioral factors that lead to undesirable pregnancy outcomes ${ }^{7}$. The lack of adequate pregnancy care creates health problems and can lead to undesirable neonatal outcomes such as abortion, stillbirth, premature birth, low birth weight and many similar problems that can impose heavy health care costs on families 8,9 .

The use of mobile technology, such as various practical applications (social networks), by the patients promotes patient education and self-management in chronic diseases and improves the possibility of the remote monitoring of the patient ${ }^{10}$.

Given the importance of online mobile social networks, which play an integral role in facilitating access to health information and the exchange of medical information and educating on the adverse effects of drugs and the physical symptoms of diseases, a good framework needs to be developed for providing health care services in health organizations in order to share pregnancy-related information among peer groups via online social networks and to accelerate pregnant women's communication with health care providers (physicians, midwives and nurses). Health organizations can then use these new technologies to improve the speed and accuracy of self-care in pregnant women. Moreover, given the widespread use of social networks (Twitter, WhatsApp, Facebook, etc.) by various social classes, particularly by young women, it is necessary to evaluate the impact of these networks in terms of health. The researcher therefore seeks to explore the role of online social networks in improving self-care in pregnant women in hospitals affiliated to Semnan University of Medical Sciences.

\section{METHODOLOGY}

This was a Observational cross-sectional study. Participants in this study were pregnant women who as inpatients and outpatients referred to Amir Almomenin hospital of Semnan University of medical sciences, Iran from November 2016 to April 2017. Four hundred and four pregnant women were estimated as sample using the sample size estimation of Cochran (confidence level of 95\%), among the ones who referred to outpatient clinic and inpatients of Amir Almomenin hospital of Semnan. We obtained ethical approval from the Medical Ethics Committee of Semnan University (IR. SEMUMS. REC.1394.230). The questionnaire used in this study included three sections and the authors developed it after reviewing the related literatures. The first section included demographic information such as age, education, number of pregnancies, education and the number of abortions. The second section contained 10 questions that measured the use of social networks by pregnant women to exchange information with each other. The third section included 7 questions that measured the use of social networks by pregnant women to exchange information with the clinical staffs. A 5-point Likert type scale was used to measure the attitudes on each criterion (Never $=1$, Very low $=2$, Low $=3$, High $=4$ Very high $=5$ ). The primary questionnaire was reviewed for content validity (through the content validity index (CVI)), and evaluated by 10 experts, who offered feedback in relation to the simplicity and clarity of questions, and the relationship between questions. The questionnaire was tested as pilot on 28 pregnant women which were randomly chosen from Amir Almomenin hospital. The reliability of second and third sections respectively gained 0.88 and 0.90 of Cronbach's alpha. Finally, in this study, after the approval of the university Ethics Committee, with coordination of hospital management, researchers went to research environment (Amir Almomenin hospital) to gather data and observance of ethics including informing statistical society about the purpose of the study, explaining that participating in this study is optional and ensuring them that their demographic information remains confidential. The questionnaire distributed among statistical society (i.e. inpatient pregnant women and the ones which referred to outpatient clinic of this hospital) in both morning and afternoon. After filling the questionnaire, they were gathered by researchers. KolmogorovSmirnoff test indicated that data distribution was normal. SPSS v.19 was used to perform descriptive statistics for determining the distributions of responses. Friedman test and one-way ANOVA were used to analyze data in significant level of 0.05 .

\section{RESULTS}

Table I presents the demographic characteristics of the participants. The participants' mean age was $28.73 \pm 5.8$ years; $149(36.9 \%)$ of them had bachelor's degrees, 273 (67.5\%) were housewife, 202 (50\%) were prim parous and 249 (61.7\%) had never experienced abortions.

The findings of the study (Table II) showed that the highest mean score $(3.46 \pm 1.33)$ of using social networks by the pregnant women pertained to using these networks to benefit from the experience of other women with children and the lowest mean score $(2.02 \pm 1.26)$ pertained to using these networks to learn about medical supplements recommended by other pregnant women. There was a significant difference between the mean scores obtained $(P<0.001)$.

The findings (Table III) showed that the highest mean score $(2.67 \pm 1.34)$ of using social networks by the 
Ghasem Deimazar, Mehdi Kahouei, Mozhgan Rahmanian, Neda Motamednejad, Parnian Mehrabi

pregnant women pertained to their concerns due to the different information provided by their physicians and by social network users, and the lowest mean score $(1.59 \pm 1.04)$ pertained to getting a prescription from the physician. There was a significant difference between the mean scores obtained $(P<0.001)$.

TABLE I:

THE STUDY SUBJECTS' CHARACTERISTICS

\begin{tabular}{|l|l|c|c|}
\hline \multicolumn{2}{|c|}{ Characteristics } & N & $\%$ \\
\hline \multirow{4}{*}{ Education } & Illiteracy & 43 & 10.6 \\
\cline { 2 - 4 } & Diploma & 102 & 25.2 \\
\cline { 2 - 4 } & Technician & 65 & 16.1 \\
\cline { 2 - 4 } & Bachelor & 149 & 36.9 \\
\cline { 2 - 4 } & M.Sc / Phd & 45 & 11.1 \\
\hline \multirow{4}{*}{$\begin{array}{l}\text { Number of } \\
\text { pregnancies }\end{array}$} & First time & 202 & 50.0 \\
\cline { 2 - 4 } & Two or three times & 168 & 41.6 \\
\cline { 2 - 4 } & $\begin{array}{l}\text { More than three } \\
\text { times }\end{array}$ & 34 & 8.4 \\
\hline \multirow{4}{*}{$\begin{array}{l}\text { Number of } \\
\text { abortions }\end{array}$} & Null & 249 & 61.7 \\
\cline { 2 - 4 } & Once & 103 & 25.5 \\
\cline { 2 - 4 } & Twice & 42 & 10.4 \\
\cline { 2 - 4 } & Thrice & 5 & 1.2 \\
\cline { 2 - 4 } & More than 3 times & 5 & 1.2 \\
\hline \multirow{4}{*}{ Job } & Housekeeper & 37 & 9.2 \\
\cline { 2 - 4 } & Employee & 94 & 23.3 \\
\cline { 2 - 4 } & Other & 273 & 67.5 \\
\hline Age(mean \pm sd) & & $28.73 \pm 5.8$ & \multicolumn{2}{|c}{} \\
\hline
\end{tabular}

TABLE II: MEAN SCORE OF PREGNANT WOMEN'S ATTITUDE ABOUT EXCHANGING INFORMATION WITH CLINICAL STAFF IN SOCIAL NETWORK

\begin{tabular}{|c|c|c|c|c|}
\hline Question & Mean & SD & $\begin{array}{c}\text { Mean } \\
\text { rank }\end{array}$ & $p$-value \\
\hline $\begin{array}{l}\text { Communication with } \\
\text { midwife or physician }\end{array}$ & 2.15 & 1.34 & 4.37 & \multirow{7}{*}{$<0.05$} \\
\hline $\begin{array}{l}\text { Anxiety because of } \\
\text { difference between } \\
\text { physician's and } \\
\text { social network users' } \\
\text { information }\end{array}$ & 2.67 & 1.34 & 5.17 & \\
\hline $\begin{array}{l}\text { Receiving medical } \\
\text { care from attending } \\
\text { physician }\end{array}$ & 2.02 & 1.30 & 4.13 & \\
\hline $\begin{array}{l}\text { Receiving medicine } \\
\text { prescription from } \\
\text { physician }\end{array}$ & 1.59 & 1.04 & 3.34 & \\
\hline $\begin{array}{l}\text { Receiving } \\
\text { sonography orders } \\
\text { from physician }\end{array}$ & 1.67 & 1.13 & 3.50 & \\
\hline $\begin{array}{l}\text { Receiving periodical } \\
\text { laboratory orders } \\
\text { from physician }\end{array}$ & 1.74 & 1.18 & 3.65 & \\
\hline $\begin{array}{l}\text { Communication with } \\
\text { attending physician } \\
\text { when needed }\end{array}$ & 1.83 & 1.19 & 3.84 & \\
\hline
\end{tabular}

TABLE II: MEAN SCORE OF PREGNANT WOMEN'S ATTITUDE ABOUT EXCHANGING INFORMATION WITH EACH OTHER IN SOCIAL NETWORK

\begin{tabular}{|l|c|c|c|c|}
\hline \multicolumn{1}{|c|}{ Question } & Mean & SD & Mean rank & p-value \\
\hline Impacts of using social networks on healthy diet & 3.20 & 1.23 & 6.50 & \\
\hline Communication with other pregnant women via social networks & 2.95 & 1.32 & 5.84 \\
\hline The amount of trust to shared information by other pregnant women & 2.85 & 1.12 & 5.46 \\
\hline Using each other's experiences about self-care & 3.01 & 1.19 & 5.98 \\
\hline Using supplementary medicine offered by other pregnant women & 2.02 & 1.26 & 3.73 \\
\hline Inquiring about finding a good physician & 2.85 & 1.42 & 5.55 \\
\hline Inquiring about newborn baby's vaccination after birth & 2.35 & 1.35 & 4.44 \\
\hline Inquiring about newborn baby's diseases after birth & 2.67 & 1.36 & 5.13 \\
\hline Using other's experiences who already have children & 3.46 & 1.33 & 7.15 \\
\hline Inquiring about the time of sonography & 2.62 & 1.36 & 5.21 & \\
\hline
\end{tabular}




\section{DISCUSSION}

The results of the present study showed that there was a significant relationship between the level of education in pregnant women and their ability to exchange information with each other on social networks. In other words, pregnant women with higher education make wider use of social networks to exchange information. Other findings of the study suggest that the pregnant women did not have much confidence in using the alternative supplements recommended by other pregnant women on social networks (mean=2.02) and only a small number of them used supplements during pregnancy without consultation with their doctor. The medicinal information provided on social networks is potentially harmful to public health and should be carefully and accurately controlled and used only under the supervision of a doctor ${ }^{11,12}$. There is limited evidence on the positive effects of online communication on the health of individuals ${ }^{13}$. The research findings demonstrated that pregnant women were more likely to use the experiences of other pregnant women who already had children, and the highest mean score pertained to this item (mean=3.46). Also, pregnant women's confidence in information shared on social media had a low mean score (mean=2.85). Antheunis et al. found that the mean uncertainty of patients was higher about the information shared on social media $(\text { mean }=3.30)^{14}$. Moorhead et al., however, showed that social network users tend to share their health information on social networks, which effectively enable a rapid access to medical information for users; meanwhile, despite the great benefits of social media in terms of health communication, there is a need to control the reliability of this information ${ }^{15}$.

The other findings of this study showed that pregnant women use their social networks to find relevant health information. Some studies have also shown that social media have a positive impact on people's health ${ }^{16}$. Pregnant women were also found to often contact other women with a history of pregnancy who shared their experiences on social networks in order to gather information on their pregnancy status. Similar studies show that patients often use social networks (Facebook, Twitter, etc.) to contact patients with similar conditions so as to find out more about their illness ${ }^{14}$.

The results of the present study indicate that pregnant women very rarely use social networks to communicate with clinical staff, which could be because there are currently no tariffs for electronic health services in Iran, and insurers do not pay for the costs of these services, which seems to be one of the reasons for physicians' lack of willingness to use social networks. Given the widespread influence of social media in the health care industry, the results of the study by Antonius et al. showed that physicians' willingness to use social media to electronically communicate with their patients regarding their health services was $14 \%$ for Twitter and $28 \%$ for Facebook ${ }^{14}$. According to the study conducted by Colineau and Paris, people use health-related social networks to discuss sensitive issues and complex information with health professionals ${ }^{13}$. Other studies also show that physicians (in Australia and the United States) frequently use social media in their personal lives, but their use for daily work (such as to communicate with their patients) is limited even in these countries ${ }^{17,18}$. McGowan BS 2012 found that $58 \%$ of physicians believed that using social media to communicate with their patients would make them more effective in patient care. Moreover, $60 \%$ of physicians believed that using social media would help them improve their care $^{19}$

Social networks have opened up new doors to contemporary health care. Social media have the potential benefits of enabling a quick access to medical information and encouraging mutual interactions with similar groups, but mandate that the shared information be controlled more effectively to protect the confidentiality of patient information on social networks. According to the findings of this research, electronic communication between pregnant women and the clinical staff (midwives and physicians) through social media requires the promotion of social network use by this group. It thus seems necessary to encourage physicians to use social media to properly monitor their patients' maternal and fetal health. Pregnant women's knowledge of the information shared on social media, such as on medications and nutrition during pregnancy, should be improved and they should take their medications under the supervision of their physician so as to prevent side-effects. According to the results, there is a need to create a suitable platform for the use of online social networks by pregnant women in Iran. It is also possible to 
encourage the use of online social networks to provide pregnant women with care services by defining tariffs for electronic health services for gynecologists, obstetricians and midwives.

\section{ACKNOWLEDGMENTS}

This publication was supported by a grant [number: 995] from the Semnan University of Medical Sciences, Semnan, Iran. We would like to thank Amir Almomenin Educational, Research and Therapeutic Centers of Semnan University of Medical Sciences for providing facilities to this work.

\section{Conflict of Interest}

There is no conflict of interest to be declared.

\section{REFERENCES}

1. Kaplan AM, Haenlein M. Users of the world, unite! The challenges and opportunities of Social Media. Business horizons 2010;53(1):59-68. DOI: 10.1016/j.bushor.2009.09.003.

2. Van de Belt TH, Berben SA, Samsom M, Engelen LJ, Schoonhoven L. Use of social media by Western European hospitals: longitudinal study. J Med Internet Research 2012;14(3): e61. doi: 10.2196/jmir.1992..

3. Fernández-Luque L, Teresa Bau. Health and social media: perfect storm of information. Healthc Inform Res 2015; 21(2):67-73. doi: 10.4258/ hir.2015.21.2.67.

4. Najafi SM, Vahedparast $H$, Hafezi $S$, Saghafi $A$, Farsi Z, Vahabi Y. Effect of self-care education on quality of life in patients suffering from myocardial infarction. Critical Care Nursing 2009; 1(1):35-9.

5. Javid FM, Simbar M, Dolatian M, Alavi Majd H. Comparison of pregnancy self-care, perceived social support and perceived stress of women with gestational diabetes and healthy pregnant women. IJEM 2014; 16(3):156-64.

6. Olds S.B. London M.L, Ladewig P.W, Davidson M.R. Clinical handbook: Maternal-Newborn Nursing \& Women's Health Care $\left(7^{\text {th }}\right.$ ed.) Pearson Prentice Hall: Upper Saddle River, NJ; 2004.

7. Heaman MI, Newburn-Cook CV, Green CG, Elliott LJ, Helewa ME. Inadequate prenatal care and its association with adverse pregnancy outcomes: a comparison of indices. BMC Pregnancy Childbirth 2008; 8(1):15. doi: 10.1186/1471-2393-8-15.

8. Soleiman Ekhtiari Y, Majlessi F, Rahimi Foroushani A. Measurement of the Constructs of Health Belief Model related to Self-care during Pregnancy in Women Referred to South Tehran
Health Network. Community Health 2015; 2(1): 9-18.

9. Wallace DA, Dodd MM, McNeil DA, Churchill AJ, Oelke ND, Arnold SL, et al. A Pregnancy Wellness Guide to Enhance Care Through Self-Assessment, Personal Reflection, and Self-Referral. J Obstet Gynecol Neonatal Nurs 2009; 38(2):134-47. doi: 10.1111/j.15526909.2009.01008.x.

10. Mosa AS, Yoo I, Sheets L. A systematic review of healthcare applications for smartphones. BMC Med Inform Decis Mak 2012; 12(1):67. doi: 10.1186/1472-6947-12-67.

11. Aikin KJ, Sullivan HW, Dolina S, Lynch M, Squiers LB. Direct-to-Consumer Promotion of Prescription Drugs on Mobile Devices: Content Analysis. J Med Internet Res 2017; 19(7):e225. doi: 10.2196/ jmir.7306.

12. Tyrawski J, DeAndrea DC. Pharmaceutical companies and their drugs on social media: a content analysis of drug information on popular social media sites. J Med Internet Res 2015; 17 (6): e130. doi: 10.2196/jmir.4357

13. Colineau N, Paris C. Talking about your health to strangers: understanding the use of online social networks by patients. New Review of Hypermedia and Multimedia 2010; 16(1-2):141-60.

14. Antheunis ML, Tates K, Nieboer TE. Patients' and health professionals' use of social media in health care: motives, barriers and expectations. Patient Educ Couns 2013; 92(3):426-31. doi: 10.1016/ j.pec.2013.06.020.

15. Moorhead SA, Hazlett DE, Harrison L, Carroll JK, Irwin A, Hoving C. A new dimension of health care: systematic review of the uses, benefits, and limitations of social media for health communication. J Med Internet Res 2013; 15(4): e85. doi: 10.2196/jmir.1933.

16. Merolli M, Gray K, Martin-Sanchez F. Health outcomes and related effects of using social media in chronic disease management: a literature review and analysis of affordances. $\mathrm{J}$ Biomed Inform. 2013; 46(6):957-69. doi: 10.1016/j.jbi.2013.04.010.

17. Bosslet GT, Torke AM, Hickman SE, Terry CL, Helft PR. The patient-doctor relationship and online social networks: results of a national survey. J Gen Intern Med 2011; 26(10):1168-74. doi: 10.1007/s11606-011-1761-2. 
18. Brown J, Ryan C, Harris A. How doctors view and use social media: a national survey. J Med Internet Res 2014; 16(12):e267. doi: 10.2196/ jmir.3589.

19. McGowan BS, Wasko M, Vartabedian BS, Miller
RS, Freiherr DD, Abdolrasulnia M. Understanding the factors that influence the adoption and meaningful use of social media by physicians to share medical information. J Med Internet Res 2012; 14(5): e117.

\begin{tabular}{|l|}
\hline \multicolumn{1}{|c|}{ AUTHOR AFFILIATION: } \\
Ghasem Deimazar \\
Health Information Technology \\
Department of Allied Health School \\
Semnan University of Medical Sciences, Semnan, Iran. \\
Mehdi Kahouei (Corresponding Author) \\
Associate Professor \\
Social Determinants of Health Research Center \\
Allied Health School of Semnan University of \\
Medical Sciences, Semnan, Iran. \\
Email: mkahouei@yahoo.com \\
Mozhgan Rahmanian \\
Associate Professor, Department of Gynecology \\
Semnan University of Medical Sciences, Semnan, Iran. \\
Neda Motamednejad \\
Student Research Committee, Faculty of Paramedics \\
Semnan University of Medical Sciences, Semnan, Iran. \\
Parnian Mehrabi \\
Student Research Committee, Faculty of Paramedics \\
Semnan University of Medical Sciences, Semnan, Iran. \\
\hline
\end{tabular}

